\title{
Mortality of copper cadmium alloy workers with special reference to lung cancer and non-malignant diseases of the respiratory system, 1946-92
}

\author{
Tom Sorahan, Andrew Lister, Mark S Gilthorpe, J Malcolm Harrington
}

\begin{abstract}
Objectives-To identify and quantify any relations between occupational exposure to cadmium oxide fume and mortalities from lung cancer and from chronic nonmalignant diseases of the respiratory system.

Methods-The mortality experience of 347 copper cadmium alloy workers, 624 workers employed in the vicinity of copper cadmium alloy work (vicinity workers), and 521 iron and brass foundry workers (all men) was investigated for the period 1946-92. All subjects were first employed in these types of work in the period 1922-78 and for a minimum period of one year at one of two participating factories. Two analytical approaches were used, indirect standardisation and Poisson regression.
\end{abstract}

Results-Compared with the general population of England and Wales, mortality from lung cancer among copper cadmium alloy workers was close to expectation (observed deaths 18, expected deaths $17 \cdot 8$, standardised mortality ratio (SMR) 101, 95\% confidence interval (95\% CI) 60 to 159). A significant excess was shown for lung cancer among vicinity workers but not among iron and brass foundry workers (vicinity workers: observed 55, expected 34.3, SMR 160, 95\% CI 121 to 209, P < 0.01; iron and brass foundry workers: observed 19, expected 17.8, SMR 107, 95\% CI 64 to 167). Increased SMRs for non-malignant diseases of the respiratory system were shown for each of the three groups (alloy workers: observed 54, expected $23 \cdot 5$, SMR $230,95 \%$ CI 172 to $300, P<0.001$; vicinity workers: observed 71 , expected $43 \cdot 0$, SMR $165,95 \%$ CI 129 to $208, P<0.001$; iron and brass foundry workers: observed 34, expected 17.1, SMR 199, 95\% CI 137 to 278, $P<0.01)$. Work histories of the copper cadmium alloy workers were combined with independent assessments of cadmium exposures over time to develop individual estimates of cumulative exposure to cadmium; this being a time dependent variable. Poisson regression was used to investigate risks of lung cancer and risks of chronic non-malignant diseases of the respiratory system in relation to three levels of cumulative cadmium exposure $\left(<1600,1600-4799, \geqslant 4800 \mu \mathrm{g}^{-m^{-3}} \cdot \mathrm{y}\right)$. After adjustment for age, year of starting alloy work, factory, and time from starting alloy work, there was a significant positive trend $(P<0.01)$ between cumulative exposure to cadmium and risks of mortality from chronic non-malignant diseases of the respiratory system. Relative to a risk of unity for the lowest exposure category, risks were $4.54(95 \%$ CI 1.96 to 10.51$)$ for the middle exposure category and 4.74 (95\% CI 1.81 to 12.43$)$ for the highest exposure category. There was a non-significant negative trend between cumulative cadmium exposure and risks of mortality from lung cancer. Relative to a risk of unity for the lowest exposure category, risks were $0.85(95 \% \mathrm{CI} 0.27$ to 2.68$)$ for the middle exposure category and 0.81 $(95 \%$ CI $0 \cdot 18$ to $3 \cdot 73)$ for the highest exposure category. Similar findings were obtained when adjustment was made for age only.

Conclusions-The findings are consistent with the hypothesis that exposure to cadmium oxide fume increases risks of mortality from chronic non-malignant diseases of the respiratory system. The findings do not support the hypothesis that exposure to cadmium oxide fume increases risks of mortality for lung cancer.

(Occup Environ Med 1995;52:804-812)

Keywords: cadmium; lung cancer; respiratory diseases

In 1953, a health survey of copper cadmium alloy workers from two factories (A and B) was carried out by Bonnell under the auspices of the Medical Research Council (MRC); findings relating to emphysema and proteinuria were reported in $1955 . .^{1}$ Of the 100 alloy workers examined, nine had emphysema and proteinuria, three had emphysema without proteinuria, and seven had proteinuria without emphysema. One hundred and four employees who had never had any work contact with copper cadmium alloy had been examined as a control group; only one case of proteinuria and one case of emphysema were diagnosed. A further group of 151 vicinity workers from factory B were examined. Vicinity workers, although employed in a workshop in which copper cadmium alloys were being made, were employed in the refining of copper and the manufacture of arsenical copper, phosphor bronze, and other copper alloys. Bonnell' reported "there were no cases in this group in whom the findings were consistent with the diagnosis of chronic cadmium poisoning." Chronic 
cadmium poisoning referred to proteinuria or emphysema induced by cadmium. In 1957, a follow up study produced diagnoses of proteinuria or emphysema in a further 24 men from the original group of 100 workers of copper cadmium alloy. ${ }^{2}$

Holden published two short reports, which included information on the mortality of men employed for at least 12 months as copper cadmium alloy workers at either of the two factories; follow up was to the end of $1979 .{ }^{34} \mathrm{~A}$ more detailed analysis has now been carried out that includes the analysis of deaths occurring in a further 13 years of follow up. Particular emphasis is given to findings for lung cancer because of the recent evaluation by an international agency for research on cancer (IARC) Working Group that there was sufficient evidence in humans for the carcinogenicity of cadmium and cadmium compounds. ${ }^{5}$ (This evaluation seemed to rely heavily on the significant relations between risks of lung cancer and estimated cumulative exposure to cadmium reported by Thun et $a l^{6}$ and Stayner et $a l^{7}$ in their analyses of mortality among a cohort of workers from a single United States cadmium recovery plant. Sorahan and Lancashire $^{8}$ have recently highlighted potentially serious problems with the data analysed by these investigators.) Emphasis is also given to findings for chronic non-malignant diseases of the respiratory system because earlier studies of health effects in this workforce found evidence of increased risks of these diseases. ${ }^{1-49}$

\section{Materials and methods \\ STUDY POPULATION}

The study cohort comprised 168 copper cadmium alloy workers from factory A, 179 copper cadmium alloy workers from factory $B$, 624 vicinity workers from factory $B$, and 521 iron and brass foundry workers from factory $B$. All of them were men. All employees worked for a minimum period of 12 months in these job categories and started the selected occupations in the period 1922-78. Ninety eight of the alloy workers who participated in the 1953 MRC survey are included in the study cohort; the remaining two workers were later judged not to have had 12 months employment as copper cadmium alloy workers. The iron and brass foundry workers were described by

Table 1 Study population by vital status at closing date of survey* and by year of start of employment

\begin{tabular}{|c|c|c|c|c|c|}
\hline & \multirow{2}{*}{$\begin{array}{l}\begin{array}{l}\text { Factory } A \\
\text { workers }\end{array} \\
\text { Alloy }\end{array}$} & \multicolumn{3}{|c|}{$\begin{array}{l}\text { Factory } B \\
\text { workers }\end{array}$} & \multirow[b]{2}{*}{ Tota } \\
\hline & & Alloy & $\begin{array}{l}\text { Vicinity } \\
\text { workers }\end{array}$ & $\begin{array}{l}\text { Brass and } \\
\text { iron foundry }\end{array}$ & \\
\hline $\begin{array}{l}\text { Traced alive } \\
\text { Dead } \\
\text { Emigrated } \\
\text { No trace } \\
\text { Total }\end{array}$ & $\begin{array}{r}29 \\
127 \\
1 \\
11 \\
168\end{array}$ & $\begin{array}{r}72 \\
102 \\
3 \\
2 \\
179\end{array}$ & $\begin{array}{r}192 \\
408 \\
14 \\
10 \\
624\end{array}$ & $\begin{array}{r}321 \\
188 \\
9 \\
3 \\
521\end{array}$ & $\begin{array}{r}614 \\
825 \\
27 \\
26 \\
1492\end{array}$ \\
\hline $\begin{array}{l}\text { Year of start of employment } \\
1922-40 \dagger \\
1940-62 \ddagger \\
1962-78 \Phi \\
\text { Total }\end{array}$ & $\begin{array}{r}134 \\
30 \\
4 \\
168\end{array}$ & $\begin{array}{r}39 \\
101 \\
39 \\
179\end{array}$ & $\begin{array}{r}0 \\
624 \\
0 \\
624\end{array}$ & $\begin{array}{r}56 \\
328 \\
137 \\
521\end{array}$ & $\begin{array}{r}229 \\
1083 \\
180 \\
1492\end{array}$ \\
\hline
\end{tabular}

*31 December 1992; †1 January 1922-31 July 1940; $¥ 1$ August 1940-31 March 1962; \$1 April 1962-31 December 1978.
Holden as a control group 416 members of Holden's original control group have now been excluded because they started employment in the foundry before 1922 .

The study populations had been abstracted by Holden from much larger sets of personnel records; the selected occupations represented only a small percentage of the total workforce at the two factories (personal communication, D O'Malley). Incomplete information on job histories were available from centralised personnel records at factory A; at factory B, starter and leaver books for the relevant departments were reviewed. (These books recorded, in chronological order, names of employees with dates of starting and leaving work in a given department.) Information obtained from these sources had been augmented by information obtained from company medical records, foremen, and long serving employees to identify those workers employed directly on the manufacture of copper cadmium alloys and those workers employed in the workshop that housed the copper cadmium process but who were never employed directly on the manufacture of copper cadmium alloys (vicinity workers). The final survey cards included information on job titles and dates carried out, dates of starting work on copper cadmium alloy and duration of alloy work.

Survey cards for all members of the cohort had been sent to the Office of Population Censuses and Surveys (OPCS); $;^{34}$ the OPCS continues to supply the principal investigator with copies of death certificates coded to the 8th revision of the international classification of disease (ICD-8) for those members of the study cohort who are dead together with embarkation details for those who have left the country. The study records have passed through several hands since the early reports ${ }^{34}$ and for the purpose of this analysis all relevant information held by OPCS was double checked with the vital status as recorded in the study computer file. A few errors were identified in the computer file and these were corrected.

Table 1 shows the vital status of the study population on the closing date of the study, 31 December 1992. Vital status was unknown for only $1.7 \%$ of the total cohort although tracing was not as successful for alloy workers from factory A (6.5\% untraced). It was not possible to obtain a copy of the death certificate for three of the deaths; these deaths appear only in tables of mortality from all causes.

Table 1 also shows the study population, and its four constituent subcohorts, by year of starting employment in the selected occupations. For the alloy workers and brass and iron foundry workers, this date refers to the date of starting alloy work or brass and iron foundry work, respectively. For the vicinity workers, this date refers to the date of starting employment in the vicinity of copper cadmium alloy manufacture. A study subject from factory B could, for example, have worked with arsenical copper from 1935 but only became a vicinity worker in 1940, when the manufacture of copper cadmium alloys was moved into the 
same workshop (see next section). By definition, all vicinity workers started this type of employment in the period 1940-62 (see next section). Most of the copper cadmium alloy workers from factory A started alloy work in the period 1922-40; most of the copper cadmium alloy workers from factory B started alloy work in the period 1940-62.

\section{FACTORY PROCESSES}

Factory $A$

Production of copper cadmium alloy began on a small scale in 1922. In 1935, production was moved to another site about three miles away. The new shop was $55 \mathrm{~m} \times 18 \mathrm{~m} \times 9 \mathrm{~m}$ high and held five banks of six small coke fired pit furnaces. Eight of the 30 furnaces were used to cast copper cadmium alloys; the others were used to cast brass, bronze, phosphor bronze, and other copper alloys.

In the early years, the master alloy was made by melting cadmium in a crucible and adding copper to make a 2:1 copper cadmium mixture. After manual stirring, the mixture was cast into blocks and the final low cadmium content alloy (about 1\% cadmium) was made by adding blocks of the master alloy to molten copper and stirring. The crucibles containing the final alloy were lifted by crane and their contents emptied into a large foundry ladle. The alloy was then poured into oil-dressed moulds measuring some $2.7 \mathrm{~m} \times 1.8 \mathrm{~m}$. There was no exhaust extraction; ventilation was supplied by side doors and by two small fans in the roof. Wartime blackout made conditions (in both factories) much worse. The mould would be filled four or five times in a working day. The casting of the master alloy was carried out by one man at the end of the shift.

Around 1952, the open furnaces were replaced by an electric rocker resistor furnace fitted with extraction equipment. The working arrangements of the improved shop were described (with accompanying diagram) by King in $1955 .^{10}$ At one end of the shop there was a series of coke fired pit furnaces, one of which was used to make the master alloy. In the middle of the shop there were induction furnaces that were used to manufacture brass and bronze, and at the other end of the shop there was the new rocker furnace used to make the final copper cadmium alloys. Some time later the mixture of the master alloy was changed to equal quantities of copper and cadmium, and the copper was melted first. Production of copper cadmium alloys ended in 1966.

\section{Factory $B$}

Production of copper cadmium alloys began in 1926 in room 128. The shop measured $27 \mathrm{~m}$ $\times 11 \mathrm{~m} \times 4 \mathrm{~m}$ high and contained three 350 $\mathrm{lb}$ coke fired hand tilting furnaces and six $120 \mathrm{lb}$ pit furnaces. Initially the shop was ventilated only by side doors and a roof louvre. In 1930, a fan was added to the gable wall. The furnaces were linked to a main flue during melting, but because the addition of cadmium and mixing were carried out manually, the extraction hoods were often pushed aside by men standing on raised platforms to carry out these tasks. A crane to lift the crucibles containing the molten alloy was introduced around 1930. In 1936, production of the final alloy was moved to a larger room (room 278) measuring $56 \mathrm{~m}$ $\times 17 \mathrm{~m} \times 8 \mathrm{~m}$ high, but production of the master alloy remained in room 128 .

In August 1940, final alloy production was moved to the west end of the main casting bay of the copper refinery and master alloy production was moved to room 278. The copper refinery was a much larger shop measuring $134 \mathrm{~m} \times 55 \mathrm{~m} \times 10 \mathrm{~m}$ high and contained three large copper refining furnaces and two casting wheels in the main body of the building. Arsenical copper, bronze, phosphor bronze, and silver bronze were cast in the central area of this workshop. At the west end (some $60-80 \mathrm{~m}$ away), the workers of copper cadmium alloy operated seven oil fired hand tilting furnaces. In 1941, fans were installed in the roof and an extraction unit was placed on the furnaces in 1954. In 1957, an enclosed casting box was installed in room 278 for master alloy production.

In April 1962, production of master and final alloys was moved to room 311 (46 m $\times$ $19 \mathrm{~m} \times 7 \mathrm{~m}$ high). This contained a single $400 \mathrm{lb}$ furnace for master alloy production and 13 oil fired Morgan tilting furnaces (each $600 \mathrm{lb}$ ) for final alloy production; other alloys were not produced in this room. In 1969, nine Morgan furnaces were replaced with five 2000 lb electric Ajax furnaces; master alloy production continued in a Morgan furnace. More powerful extraction equipment was added in 1981 and the process remained largely unchanged until the factory ended production of copper cadmium alloys in 1989.

\section{ESTIMATION OF CUMULATIVE CADMIUM} EXPOSURES

As part of a study into inhalation of cadmium fume and emphysema among copper cadmium alloy workers at factory B, Davison et al reviewed 933 measurements of airborne cadmium made between 1951 and 1983 (697 with static samplers and 236 with personal samplers). ${ }^{9}$ Cadmium exposures were estimated "by consideration of all available measurements, changes in production techniques, ventilation, and levels of production and from discussions with the occupational health physician, industrial hygienist, the management, and the work force." Table 2 shows the final exposure assessments, which have been used to estimate individual cumulative exposures to cadmium as a time dependent variable. The cumulative exposure for each man who worked with copper cadmium alloy was calculated as the sum of the estimated exposures to cadmium during each year (or proportion, if part of a year) worked with copper cadmium alloy in the period 1922-80, expressed in $\mu \mathrm{g} \cdot \mathrm{m}^{-3} . \mathrm{y}$. The exposure matrix relating to factory $B$ (table 2) was also used to estimate cumulative exposures to cadmium for the alloy workers from factory A. Similar estimates were not available for vicinity workers, but static 
sampling results reported by King in 1955 are consistent with vicinity workers having about $10 \%$ of the cadmium exposures received by alloy workers (alloy section: mean exposure to cadmium $69.6 \mu \mathrm{g} \cdot \mathrm{m}^{-3}, \mathrm{n}=25$; vicinity workers: mean cadmium exposures $6 \cdot 16$ $\left.\mu \mathrm{g} \cdot \mathrm{m}^{-3}, \mathrm{n}=26\right)$.

\section{EXTERNAL STANDARD}

The mortality experience of this cohort was compared with that which might have been expected to occur if mortalities for the general population of England and Wales had been operating on the study cohort, with due regard to the composition of the study cohort by age (five-year age groups), sex (men only), and calendar year (five-year calendar periods).

Expectations based on person-years at risk were calculated with the PERSONYEARS computer program. ${ }^{11}$ Men entered the person-years at risk at the end of the first year of relevant employment or 1 January 1946, whichever was the later. (For analysis of mortality among members of the 1953 MRC survey, men entered the person-years at risk on 1 January 1954.) Men left the person-years at risk on the date of death, date of embarkation, date last known alive, or the closing date of the study (31 December 1992), whichever was the earlier. Men were censored on reaching their 85 th birthday - that is, they made no further contributions to expected or observed numbers past this age. The rationale for this procedure has been supplied previously. ${ }^{12}$

Standardised mortality ratios (SMRs) were calculated as the ratio of observed to expected numbers of deaths expressed as a percentage. In calculating $P$ values and confidence intervals (CIs), it has been assumed that deaths occur as a Poisson process. Where significance tests have been carried out, two tailed tests were used.

INTERNAL STANDARD: POISSON REGRESSION Five variables were considered to have the

Table 3 Copper cadmium alloy workers $(n=347)$ : cancer mortality and mortality from other causes, 1946-92

\begin{tabular}{|c|c|c|c|c|}
\hline Cause of death & $I C D-8$ & Obs & $\operatorname{Exp}$ & $S M R(95 \% C I)$ \\
\hline \multicolumn{5}{|l|}{ Cancer: $\dagger$} \\
\hline Mouth & $143-145$ & 1 & $0 \cdot 14$ & 724 (18 to 4033$)$ \\
\hline Oesophagus & 150 & 0 & $1 \cdot 31$ & $0(0$ to 282$)$ \\
\hline Stomach & 151 & 5 & $5 \cdot 13$ & 97 (32 to 227$)$ \\
\hline Large intestine & 153 & 5 & $2 \cdot 87$ & $174(57$ to 407$)$ \\
\hline Rectum & 154 & 2 & $2 \cdot 13$ & $94(11$ to 339$)$ \\
\hline Pancreas & 157 & 4 & $1 \cdot 84$ & 218 (59 to 558$)$ \\
\hline Lung & $162-163$ & 18 & $17 \cdot 84$ & $101(60$ to 159$)$ \\
\hline Prostate & 185 & 2 & $2 \cdot 83$ & $71(9$ to 255$)$ \\
\hline Bladder & 188 & 3 & $1 \cdot 80$ & 167 (34 to 487 ) \\
\hline Other urinary & 189 & 2 & 0.74 & 272 (33 to 983 ) \\
\hline Brain & $191-192$ & 1 & 0.82 & 121 (3 to 677 ) \\
\hline Lymphoma & 200,202 & 2 & 0.68 & 293 (35 to 1058 ) \\
\hline Hodgkin's & 201 & 1 & $0 \cdot 28$ & 362 (9 to 2018 ) \\
\hline Leukaemia & $204-207$ & 2 & 0.96 & 209 ( 25 to 756$)$ \\
\hline All neoplasms & $140-239$ & 52 & 44.94 & $116(86$ to 152$)$ \\
\hline \multicolumn{5}{|l|}{ Non-cancers: } \\
\hline Circulatory system & $398-458$ & 88 & $85 \cdot 31$ & $103(83$ to 127$)$ \\
\hline Respiratory system & $460-519,866 \ddagger$ & 54 & 23.52 & $230^{\star \star \star}(172$ to 300$)$ \\
\hline Digestive system & $520-577$ & 9 & $4 \cdot 81$ & 187 (86 to 355$)$ \\
\hline Genitourinary system & $580-629$ & 3 & $2 \cdot 74$ & $110(23$ to 320$)$ \\
\hline Accidents & $800-9498$ & 2 & 3.69 & $54(7$ to 196$)$ \\
\hline Suicide & $950-959^{\circ}$ & 1 & 1.70 & $59(1$ to 328$)$ \\
\hline All causes & 1-999 & 217 & $175 \cdot 64$ & $124^{\star \star}(108$ to 141$)$ \\
\hline
\end{tabular}

$\star \star P<0.01 ; \star \star \star P<<0.001 ;+$ Sites of cancer for which there were no observed deaths and for which the expectation was less than 1.0 are not shown in the table. ICD-8 codes (and expectations) were as follows: $140-141(0 \cdot 19), 142(0.06), 146-149(0.30), 152(0.08), 155(0 \cdot 03)$ $158-159(0 \cdot 18), 160(0 \cdot 09), 161(0 \cdot 45), 172-1$
$203(0 \cdot 44) ; \ddagger$ see text; $\$$ excluding 866 (see text). potential for influencing mortality within the cohort: age (age at follow up or age at death), year of starting alloy work, factory, time from starting alloy work, and estimated cumulative exposure to cadmium. These variables were not treated as continuous, but rather each variable was categorised into a number of levels. In constructing the models, it was necessary to ensure that there was at least one death observed at each level of each variable. Any adjustments were made before any statistical modelling was carried out. Age, time from starting alloy work, and estimated cumulative exposure to cadmium are time dependent variables and the analysis allowed, therefore, for subjects to contribute person-years at risk to contemporaneous categories.

It had been intended to use the cut off values selected by Thun $e t a l^{6}$ for the categories of cumulative exposure to cadmium (working lifetime $(40 \mathrm{y})$ at a time weighted average (TWA) of $40 \mu \mathrm{g} \cdot \mathrm{m}^{-3}\left(1600 \mu \mathrm{g} \cdot \mathrm{m}^{-3}\right.$.y or $584 \cdot 4$ $\mathrm{mg} \cdot \mathrm{m}^{-3}$.days) and working lifetime at 200 $\mu \mathrm{g} \cdot \mathrm{m}^{-3}\left(8000 \mu \mathrm{g} \cdot \mathrm{m}^{-3}\right.$.y or $2922 \mathrm{mg} \cdot \mathrm{m}^{-3}$.days)). The use of these values would have placed a relatively small percentage $(8 \%)$ of observed deaths in the highest dose category so the higher of the two cut off values was reduced to $4800 \mu \mathrm{g} \cdot \mathrm{m}^{-3} \cdot \mathrm{y}\left(1753 \cdot 2 \mathrm{mg} \cdot \mathrm{m}^{-3}\right.$.days). Analyses were also carried out with exposures lagged by 10 years - that is, exposures were assumed to have no effect until 10 years had elapsed. This procedure was accomplished by adding 10 years to the dates of transition from one exposure category to another. (Thus a worker who accumulated $1600 \mu \mathrm{g} \cdot \mathrm{m}^{-3}$.y of cadmium exposure on 10 January 1951, would not accumulate this amount of lagged exposure until 10 January 1961.)

The EPICURE ${ }^{13}$ computer program was used to provide both person-years at risk and numbers of deaths for causes of interest for all combinations of all levels of the above variables and to carry out statistical modelling by means of Poisson regression. ${ }^{14}$ The purpose of the modelling was to establish whether the mortality experienced by the study cohort, and in particular the mortality experienced by the different cumulative exposure groups, could be described easily in terms of variables such as age and factory (covariates), or whether the inclusion of cumulative exposure to cadmium made a significant contribution to the ability of the overall model to describe the data. The significance of this contribution was assessed by the likelihood ratio test that compared deviance and degrees of freedom with and without inclusion of the cumulative cadmium exposure variable. Also, the significance of any trend in risk across the three exposure categories was assessed by repeating the analysis while treating cumulative exposure as a continuous variable coded 1,2 , or 3 for the three levels of exposure.

\section{Results}

EXTERNAL STANDARD

Table 3 shows observed and expected numbers of deaths both for cancer by site and for broad groupings of non-cancers; results relate to 
Table 4 Mortality of occupational groups from lung cancer and non-malignant diseases of the respiratory system, by time from starting employment, 1946-92

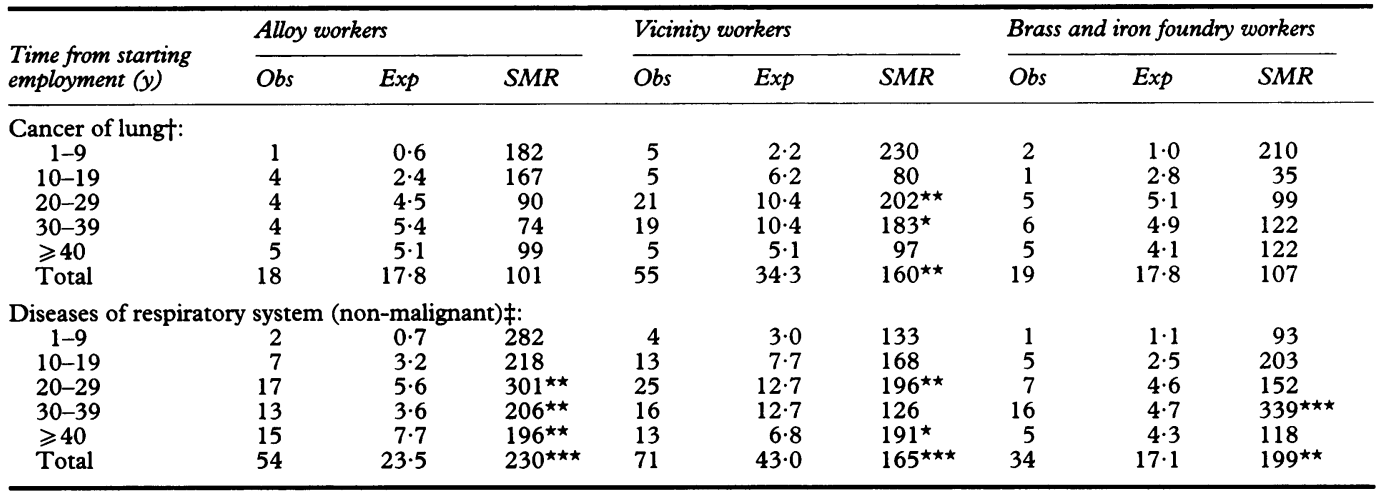

${ }^{\star} \mathrm{P}<0.05 ;{ }^{\star \star} \mathrm{P}<0.01 ;{ }^{\star \star \star} \mathrm{P}<0.001 ;+$ ICD 8th: $162-163 ; \ddagger$ ICD 8th: 460-519 and 866.

Table 5 Mortality of occupational groups from all causes, lung cancer, and non-malignant diseases of the respiratory system by entry cohort, 1946-92

\begin{tabular}{|c|c|c|c|c|c|c|c|c|c|c|}
\hline \multirow[b]{2}{*}{ Subgroup } & \multirow[b]{2}{*}{ Factory } & \multicolumn{3}{|c|}{$1922-40+$} & \multicolumn{3}{|c|}{$1940-62 \ddagger$} & \multicolumn{3}{|c|}{$1962-785$} \\
\hline & & Obs & $\operatorname{Exp}$ & $S M R$ & $O b s$ & $\operatorname{Exp}$ & $S M R$ & Obs & $\operatorname{Exp}$ & $S M R$ \\
\hline \multicolumn{11}{|l|}{ All causes: } \\
\hline $\begin{array}{l}\text { Copper cadmium } \\
\text { alloy }\end{array}$ & A & 97 & $84 \cdot 8$ & 114 & 20 & $18 \cdot 5$ & 108 & 1 & $0 \cdot 7$ & 142 \\
\hline $\begin{array}{l}\text { Copper cadmium } \\
\text { alloy }\end{array}$ & B & 31 & $22 \cdot 5$ & 138 & 62 & $45 \cdot 2$ & $137^{\star}$ & 6 & $4 \cdot 0$ & 150 \\
\hline Vicinity workers & B & 1 & 223 & 100 & 391 & 328.9 & $119^{\star \star \star}$ & - & - & 130 \\
\hline Brass and iron foundry & B & 36 & $36 \cdot 1$ & 100 & 129 & 110.9 & 116 & 22 & $16 \cdot 8$ & 131 \\
\hline \multicolumn{11}{|l|}{ Cancer of lungा: } \\
\hline $\begin{array}{l}\text { Copper cadmium } \\
\text { alloy }\end{array}$ & A & 2 & $8 \cdot 3$ & $24\left({ }^{\star}\right)$ & 1 & 1.9 & 52 & 0 & $0 \cdot 1$ & 0 \\
\hline $\begin{array}{l}\text { Copper cadmium } \\
\text { alloy }\end{array}$ & B & 4 & $2 \cdot 2$ & 181 & 9 & $5 \cdot 0$ & 181 & 2 & $0 \cdot 4$ & \\
\hline Vicinity workers & B & - & - & - & 55 & $34 \cdot 3$ & $160^{\star \star}$ & 2 & - & - \\
\hline Brass and iron foundry & B & 3 & $3 \cdot 8$ & 78 & 13 & $12 \cdot 2$ & 106 & 3 & 1.8 & 169 \\
\hline \multicolumn{11}{|c|}{ Diseases of respiratory system (non-malignant) $\|:$} \\
\hline Copper cadmium & A & 26 & $12 \cdot 4$ & $210^{\star \star}$ & 4 & $2 \cdot 4$ & 167 & 0 & $0 \cdot 1$ & 0 \\
\hline $\begin{array}{l}\text { Copper cadmium } \\
\text { alloy }\end{array}$ & B & 9 & $3 \cdot 2$ & $283^{\star}$ & 13 & $5 \cdot 3$ & $247^{\star \star}$ & 2 & $0 \cdot 2$ & 826 \\
\hline Vicinity workers & B & - & - & - & 71 & $43 \cdot 0$ & $165^{\star \star \star}$ & - & - & - \\
\hline Brass and iron foundry & B & 8 & $4 \cdot 6$ & 173 & 24 & $11 \cdot 3$ & $213^{\star \star}$ & 2 & $1 \cdot 2$ & 163 \\
\hline \multicolumn{11}{|c|}{ All causes other than lung cancer and non-malignant diseases of respiratory system: } \\
\hline $\begin{array}{l}\text { Copper cadmium } \\
\text { alloy }\end{array}$ & A & 69 & $64 \cdot 1$ & 108 & 15 & $14 \cdot 2$ & 106 & 1 & 0.6 & 179 \\
\hline Copper cadmium & & & & & & & & & 3.4 & \\
\hline Vicinity workers & B & 18 & $17 \cdot 1$ & 100 & $\begin{array}{r}40 \\
265\end{array}$ & $\begin{array}{r}34 \cdot 9 \\
251 \cdot 6\end{array}$ & $\begin{array}{l}115 \\
105\end{array}$ & 2 & $3 \cdot 4$ & 59 \\
\hline Brass and iron foundry & $\mathbf{B}$ & 25 & $27 \cdot 7$ & 90 & 92 & $87 \cdot 4$ & 105 & 17 & $13 \cdot 8$ & 123 \\
\hline
\end{tabular}

$\star P<0.05 ; \star \star P<0.01 ; \star \star \star P<0.001 ;()$ indicates deficit; +1 January 1922-31 July 1940; $¥ 1$ August 1940-31 March 1962; \$1 April 1962-31 December 1978; ๆICD 8th: 162-163; |ICD 8th: 460-519, and 866.

copper cadmium alloy workers from the two factories combined. Compared with the general population of England and Wales, there were significant excesses of non-malignant diseases of the respiratory system (observed deaths 54, expected 23.52, SMR 230, 95\% CI 172 to $300, P<0.001$ ) and for mortality from all causes (observed 217, expected 175.64, SMR 124, 95\% CI 108 to $141, P<0.01$ ). There was no significant excess for all causes excluding non-malignant diseases of the respiratory system (observed 163 , expected $152 \cdot 12$, SMR 107, 95\% CI 93 to 126). Observed and expected numbers of deaths from non-malignant diseases of the respiratory system included findings for ICD-8 E866 (accidental poisoning by heavy metals and their fumes). A total of 20 deaths were classified under this rubric; 17 of these death certificates indicated that death was due to chronic non-malignant disease of the respiratory system caused by chronic cadmium poisoning. Findings for cancer of the lung (observed 18, expected $17 \cdot 84$, SMR 101, 95\% CI 60 to 159) and cancer of the prostate (observed two, expected 2.83, SMR $71,95 \%$ CI nine to 255 ) were unexceptional.

Table 4 shows observed and expected numbers of deaths from lung cancer and nonmalignant diseases of the respiratory system by successive 10-year periods from first employment in the selected occupations; results are shown for copper cadmium alloy workers, vicinity workers, and brass and iron foundry workers. For lung cancer, a significant overall excess is shown for vicinity workers only. There are notable excesses in later periods of follow up, 20-39 years from starting local work. For non-malignant diseases of the respiratory system, significant overall excesses are shown for all three sub-cohorts. For earlier ( $<20$ years) and later ( $\geqslant 20$ years) periods of follow up the SMRs were similar.

Table 5 shows observed and expected numbers of deaths for all causes, lung cancer, nonmalignant diseases of the respiratory system and a large remainder category (all causes other than lung cancer and non-malignant dis- 
Table 6 Mortality in participants of the 1953 MRC study into men casting copper cadmium alloys, 1954-92

\begin{tabular}{|c|c|c|c|c|c|}
\hline \multicolumn{2}{|c|}{ Group in 1953 surveyt } & Factory & Obs & $\operatorname{Exp}$ & SMR $(95 \% C I)$ \\
\hline $\begin{array}{l}\text { All causes: } \\
\text { 1A } \\
\text { 1B } \\
\text { II } \\
\text { CB }\end{array}$ & $\begin{array}{l}\text { alloy workers } \\
\text { alloy workers } \\
\text { vicinity workers } \\
\text { control group }\end{array}$ & $\begin{array}{l}\text { A } \\
\mathbf{B} \\
\mathbf{B} \\
\mathbf{B}\end{array}$ & $\begin{array}{r}48 \\
31 \\
167 \\
21\end{array}$ & $\begin{array}{r}38 \cdot 4 \\
20 \cdot 0 \\
143 \cdot 8 \\
28 \cdot 1\end{array}$ & $\begin{array}{l}125(92 \text { to } 166) \\
153^{\star}(105 \text { to } 220) \\
116(99 \text { to } 135) \\
75(46 \text { to } 114)\end{array}$ \\
\hline $\begin{array}{l}\text { Cancer of } 1 \\
\text { 1A } \\
\text { 1B } \\
\text { II } \\
\text { CB }\end{array}$ & $\begin{array}{l}\text { lungł: } \\
\text { alloy workers } \\
\text { alloy workers } \\
\text { vicinity workers } \\
\text { control group }\end{array}$ & $\begin{array}{l}\text { A } \\
\text { B } \\
\text { B } \\
\text { B }\end{array}$ & $\begin{array}{r}1 \\
3 \\
21 \\
0\end{array}$ & $\begin{array}{r}4 \cdot 0 \\
2 \cdot 2 \\
15 \cdot 3 \\
2 \cdot 9\end{array}$ & $\begin{array}{c}25(1 \text { to } 141) \\
135(28 \text { to } 396) \\
137(85 \text { to } 210) \\
0(0 \text { to } 126)\end{array}$ \\
\hline $\begin{array}{l}\text { Diseases of } \\
\text { 1A } \\
\text { 1B } \\
\text { II } \\
\text { CB }\end{array}$ & $\begin{array}{l}\text { f the respiratory s } \\
\text { alloy workers } \\
\text { alloy workers } \\
\text { vicinity workers } \\
\text { control group }\end{array}$ & $\begin{array}{l}\text { (non-mali } \\
\text { A } \\
\text { B } \\
\text { B } \\
\text { B }\end{array}$ & $\begin{array}{r}14 \\
9 \\
32 \\
2\end{array}$ & $\begin{array}{r}5 \cdot 7 \\
2 \cdot 4 \\
19 \cdot 5 \\
3 \cdot 7\end{array}$ & $\begin{array}{c}245^{\star \star}(134 \text { to } 411) \\
368^{\star \star}(168 \text { to } 699) \\
164^{\star}(112 \text { to } 231) \\
54 \text { (6 to } 194)\end{array}$ \\
\hline $\begin{array}{l}\text { All causes } \\
\text { 1A } \\
\text { 1B } \\
\text { II } \\
\text { CB }\end{array}$ & $\begin{array}{l}\text { other than lung ce } \\
\text { alloy workers } \\
\text { alloy workers } \\
\text { vicinity workers } \\
\text { control group }\end{array}$ & $\begin{array}{l}\text { nd non-n } \\
\text { A } \\
\text { B } \\
\text { B } \\
\text { B }\end{array}$ & $\begin{array}{r}\text { nant c } \\
33 \\
19 \\
114 \\
19\end{array}$ & $\begin{array}{r}\text { of respi } \\
28 \cdot 7 \\
15 \cdot 4 \\
109 \cdot 0 \\
21 \cdot 5\end{array}$ & $\begin{array}{l}\text { system: } \\
115(79 \text { to } 161) \\
123(74 \text { to } 193) \\
105(86 \text { to } 126) \\
88(53 \text { to } 138)\end{array}$ \\
\hline
\end{tabular}

${ }^{\star} P<0.05,{ }^{\star \star} P<0.01 ;+$ See reference ${ }^{1}$ for description of groups $1 \mathrm{~A}, 1 \mathrm{~B}$, etc. All 58 members of the original group $1 \mathrm{~A}$ were identified, all 42 members of the original group $1 \mathrm{~B}$ were identified, and 42 members of the original group CB were identified. Membership of the original group II was “over identified” (see text); ¥ICD 8th: 162-163; \ICD 8th: 460-519, and 866.

eases of the respiratory system) by year of starting employment for each of the four subcohorts. Alloy workers from factories A and B have, overall, similarly increased SMRs for non- malignant diseases of the respiratory system (factory A: observed 30, expected 14.8, SMR 202, $95 \%$ CI 136 to $289, \mathrm{P}<0.001$; factory B: observed 24, expected 8.7, SMR 276, $95 \%$ CI 177 to $410, \mathrm{P}<0.001$ ) and similarly unincreased SMRs for the category all causes other than lung cancer and non-malignant diseases of the respiratory system (factory A: observed 85, expected 78.9, SMR 108, 95\% CI 86 to 133; factory B: observed 60, expected $55 \cdot 4$, SMR $108,95 \%$ CI 83 to 139 ). A similar pattern is shown for each of the three entry cohorts, albeit these comparisons are based on relatively small numbers. The alloy workers from factories $A$ and $B$ have, however, very different overall SMRs for lung cancer (factory A: observed three, expected $10 \cdot 3$, SMR 29, 95\% CI 6 to 86, $\mathrm{P}<0.05$; factory $\mathrm{B}$ : observed 15, expected $7 \cdot 6$, SMR $198,95 \%$ CI 111 to 325 , $P<0.05)$. A similar pattern is also shown for each of the three entry cohorts. The SMRs for lung cancer among alloy workers from factory A for the calendar year periods $1946-80$ and 1981-92 were 25 (based on two deaths) and 42 (based on one death), respectively (not shown in table).

Table 6 shows observed and expected numbers of deaths for four different cause groups of the participants of the 1953 MRC survey. It was not possible to identify the members of the control group from factory $A$ in the 1953 survey. The 1955 paper by Bonnell indicated that 151 vicinity workers were examined in the 1953 survey. ${ }^{1}$ The record cards for the mortality study, however, indicated that 237 employees were members of the original group of vicinity workers, and it is this group that is described in table 6 . The alloy workers (both factories combined) have a notable excess mortality from non-malignant diseases of the respiratory system (observed 23, expected $8 \cdot 1$, SMR 284, 95\% CI 180 to $426, \mathrm{P}<0.001$ ) but no excess mortality from lung cancer (observed 4, expected $6 \cdot 2$, SMR $65,95 \%$ CI 18 to 165 ).

INTERNAL STANDARD

At the outset of this updated analysis, cancer of the lung (ICD-8 162-163) and chronic nonmalignant diseases of the respiratory system (ICD-8 490-519) were selected for further study. Cases were selected as those deaths for which any part of the death certificate $(1 \mathrm{a}, 1 \mathrm{~b}$, 1c, or II) would be coded to the above categories. Occupational exposure to cadmium was not expected to have a discernible influence on many causes of death. Consequently, mortality from all causes excluding lung cancer, nonmalignant chronic diseases of the respiratory system, and nephritis and nephrosis was also studied to assess the usefulness of the explanatory variables used in the statistical models.

Table 7 provides relative risks (12 separate analyses) by levels of estimated cumulative exposures to cadmium (three levels: < 1600, $\left.1600-4799, \geqslant 4800 \mu \mathrm{g} \cdot \mathrm{m}^{-3} \cdot \mathrm{y}\right)$ and based solely on the experience of the 347 copper cadmium alloy workers. Table 7 also includes summaries of 12 further analyses that assessed the significance of any trends of risk across the three exposure levels. Cumulative exposure to cadmium is analysed simultaneously either with (left hand side of table) age (seven levels: 45-54, 55-59, 60-64, 65-69, 70-74, 75-79, 80-84) or with (right hand side of table) age, year of starting alloy work (four levels: $1922-39,1940-49,1950-59,1960-78)$, factory (two levels: A, B), and time since starting alloy work (five levels: 1-9, 10-19, 20-29, $30-39, \geqslant 40 \mathrm{y})$. The top half of the table relates to unlagged exposures; the bottom half of the table relates to exposures lagged by 10 years. The inclusion of the variable cumulative exposure to cadmium made a highly significant improvement to the models for chronic nonmalignant diseases of the respiratory system; there were notably increased relative risks for this cause of death. The inclusion of the variable cumulative exposure to cadmium did not approach a significant improvement to the models for lung cancer; relative risks for this cause of death were close to (or below) unity.

Findings were not materially changed when the analysis was restricted to copper cadmium alloy workers from factory B. For example, the corresponding relative risks for the point estimates of 0.50 and 0.46 (table 7) for cancer of the lung were $1.34(95 \%$ CI 0.44 to $4.05)$ and $0.54(95 \%$ CI 0.12 to 2.56$)$. Corresponding relative risks for the point estimates of 3.46 and 3.32 shown for chronic nonmalignant diseases of the respiratory system were $5 \cdot 47(95 \%$ CI $2 \cdot 11$ to $14 \cdot 19)$ and $3 \cdot 19$ (95\% CI 1.06 to 9.61$)$. When the analysis was restricted to copper cadmium alloy workers from factory $\mathrm{A}$, corresponding relative risks for chronic non-malignant diseases of the respiratory system were 3.00 ( $95 \%$ CI 0.68 to 13.30 ) and $4.30(95 \% \mathrm{CI} 0.99$ to $18 \cdot 66)$. Findings were not obtained for cancer of the lung because there were only three deaths available for analysis.

It was possible to gain an independent 
Table 7 Relative riskst for cancer of the lung and chronic diseases of the respiratory system (non-malignant) by level of cumulative exposure

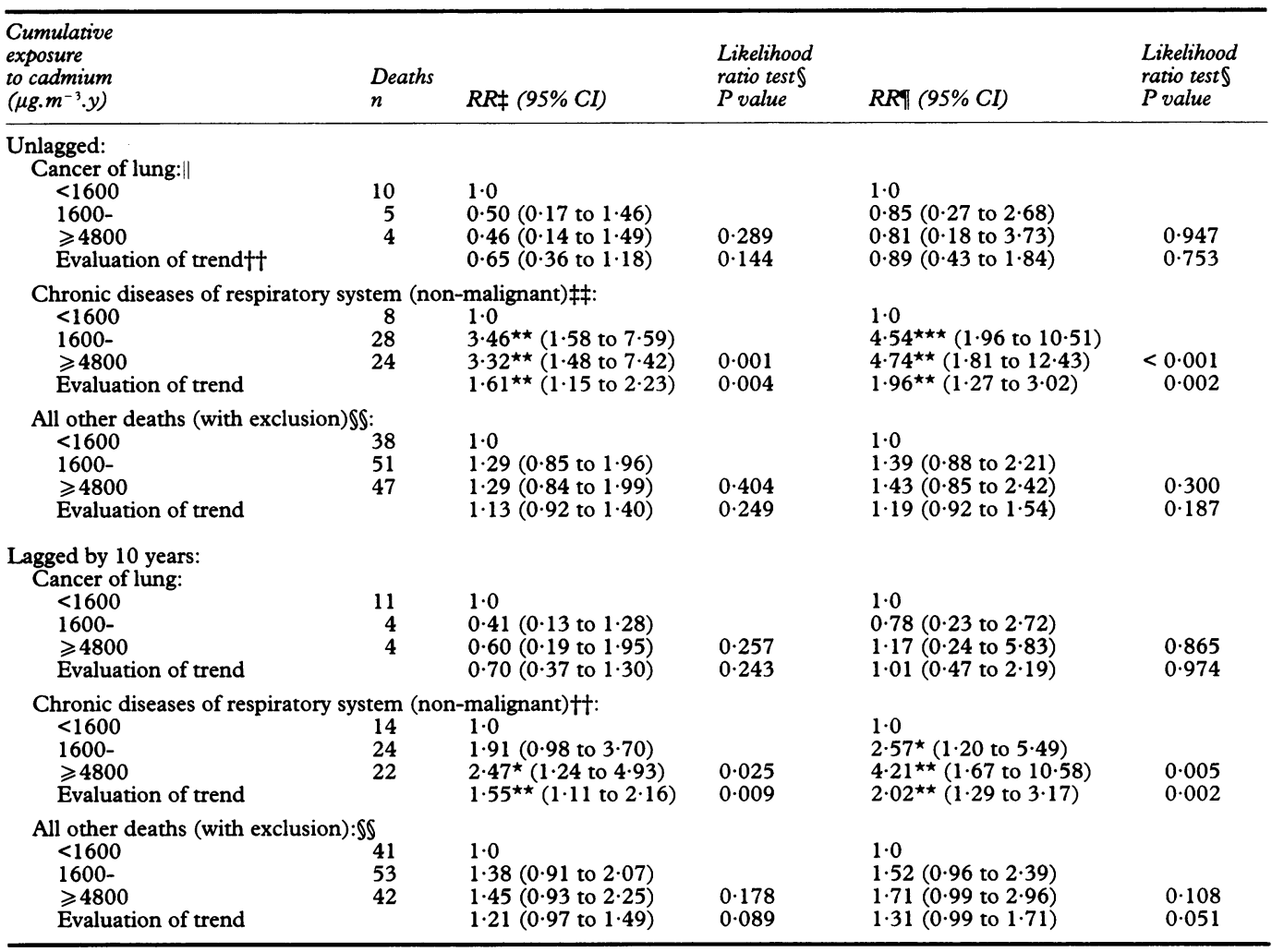

$\star P<0.05 ;{ }^{\star \star} \mathrm{P}<0.01 ;{ }^{\star \star \star} \mathrm{P}<0.001$

†Based on the mortality experience of the 347 copper cadmium alloy workers.

Adjustment for age (see text for levels).

§Difference between the deviance for a model that includes the variable cumulative exposure to cadmium and the deviance for a model that excludes this variable. This difference is interpreted as a $\chi^{2}$ value with degrees of freedom equal to the number of terms added to the fuller model $^{14}$ (three terms for the analyses by level of exposure, or one term for the analyses which evaluated trends). IAdjustment for age, year of start of alloy work, factory, and time since starting alloy work (see text for levels).

IAdjustment for age, year of start of alloy work, factory

$\| \mathrm{ICD}-8,162-163$, underlying or contributory cause.
+ tRelative risk for change in exposure of one level.

†Relative risk for change in exposure of one level.
HCD-8, 490-519, underlying or contributory cause

\#ICD-8, 490-519, underlying or contributory cause.
ISExcludes any death certificate with underlying or contributory cause coded to $162-163,490-519$, or $580-584$.

assessment of the likely reliability of the estimates of cumulative exposure to cadmium used in this report by comparing individual estimates with in vivo measurements of cadmium in liver. These measurements were obtained from neutron activation analysis and were included in the findings reported by Davison et al..$^{9}$ In vivo data were available for 68 copper cadmium alloy workers in the cohort reported here; the spearman rank correlation coefficient between the in vivo measurements of cadmium in liver and the estimated cumulative exposures to cadmium (based on job histories and the job exposure matrix shown in table 2) was $0.55 \quad(n=68$, $\mathrm{P}<0.001$ ).

\section{Discussion}

This analysis has provided very different findings for non-malignant diseases of the respiratory system and lung cancer among copper cadmium alloy workers. For non-malignant diseases of the respiratory system there were significantly increased SMRs for alloy workers from each of the two factories. Also, the Poisson regression analysis, which used an internal standard, found that mortality risks increased with estimated cumulative exposure to cadmium. For lung cancer, there was a significantly depressed SMR for copper cadmium alloy workers from factory $A$ and a significantly increased SMR for copper cadmium alloy workers from factory $B$. The Poisson regression analysis did not find cumulative exposure to cadmium to be an important risk factor for lung cancer, even when the analysis was restricted to alloy workers from factory $B$.

The unusually low SMR for lung cancer among copper cadmium alloy workers from factory A was unexpected and possible reasons for this deficit were examined in some detail. The possibility of a major artifact (such as a group of lung cancer cases being inadvertently excluded from the study) was investigated. Such an exclusion could not have taken place after the cohort was traced by the OPCS because all data supplied by the OPCS in the lifetime of the study have been checked with the current computer files. It does not seem to have taken place at the time the cohort was defined-for example, if records for lung cancer cases known to the company had been filed 
separately from the source data used for this study-because the relevant SMR was low both for the period after the date of data collection (1981-92) and for the earlier period. Moreover, in 1980, health concerns for workers exposed to cadmium centred on cancer of the prostate, renal damage, and non-malignant diseases of the respiratory system; no survey was in progress at factory $\mathrm{A}$ on the topic of lung cancer. The findings for mortality among the participants of the 1953 MRC survey also add weight to the view that the deficit is not the result of an artifact in data collection, because data for the MRC survey were collected more than 20 years before this study was initiated. Some of the deficit may be due to regional differences; factory A was situated in a rural setting whereas factory B was in an urban setting. The lifestyles of alloy workers from the two factories may well have been similar; findings for all other causes of death combined would support this view. Many SMRs were calculated; it is not particularly surprising, therefore, that one of them should describe a significant deficit. It was not possible to assess the role of cigarette smoking in this deficit.

It was also important to gain some independent evidence of whether the individual cumulative estimates of exposure to cadmium used in the Poisson regression analyses provided reliable estimates of true exposures. Some supporting evidence was provided by the comparison of cumulative exposure estimates to cadmium with in vivo measurements of cadmium in liver; liver cadmium concentration has been found to be "proportional to duration and intensity of cadmium exposure in workers without as well as with renal dysfunction."15 Further reassurance was provided by the positive Poisson regression findings for chronic non-malignant diseases of the respiratory system. These findings were not unexpected given what is already known about emphysema in copper cadmium alloy workers from these factories. ${ }^{1-4} 9$

These data have limitations. Data on smoking histories were not available, although there is no reason to think that they would be correlated with the employment histories analysed in this study. More importantly, perhaps, quantitative data on occupational exposures other than cadmium were also not available. The subcohort of iron and brass foundry workers had been referred to by Holden ${ }^{4}$ as a control group, on the grounds that such employees were not exposed to cadmium but probably had similar social characteristics. They were working, however, in an extremely dirty environment and were exposed to considerable amounts of other chemicals, including polycylic aromatic hydrocarbons. It is these other exposures that were probably responsible, at least in part, for the increased SMRs for nonmalignant diseases of the respiratory system found in this group of workers. Likewise, the vicinity workers were exposed to a different mixture of chemicals and this mixture included arsenic. Arsenic exposure may be responsible, at least in part, for the increased SMRs obtained for lung cancer in this group of work- ers. ${ }^{16}$ Exposure to cadmium would seem an unlikely explanation given that Bonnell ${ }^{1}$ found "no cases in this group in whom the findings were consistent with the diagnosis of chronic cadmium poisoning" and given that King found relatively low levels of cadmium oxide fume in those parts of the workshop distant from the cadmium operations. ${ }^{10}$ Arsenic exposure may also be responsible, at least in part, for the increased SMR found for copper cadmium alloy workers from factory B. These workers could have been exposed to arsenic in the general workshop environment or from unrecorded job rotations in the workshop. It is not inconceivable that a common exposure (which by definition could not be cadmium) was responsible for the similarly increased SMRs found for non-malignant diseases of the respiratory system among the copper cadmium alloy workers, the vicinity workers, and the iron and brass foundry workers, even though there was a positive association between risks of mortality and estimated cumulative exposure to cadmium among the copper cadmium alloy workers.

The study is also limited in that an independent historical assessment of cadmium exposures was only available for factory B. Its use for the copper cadmium alloy workers at factory A must have led to some errors in individual annual exposure estimates; misclassification relating to placement in one or more of the three levels of cumulative exposure used in the Poisson regression analysis, however, was probably modest given that processes were broadly similar and that improvements were made over time at both factories. Because the classification of work histories involved the help of former employees, it follows that the subcohorts could not now be accurately reabstracted from factory records. This is an unattractive but unavoidable feature of this study. Finally, if non-malignant diseases of the respiratory system and lung cancer are, in fact, long term sequelae of exposure to cadmium oxide fume, then the toll of mortality from nonmalignant disease may have acted as a cause of death competing with the lung cancer mortality in this study. Even taken together, however, the above limitations do not explain why the findings for lung cancer were so different from those for non-malignant diseases of the respiratory system.

In conclusion, the copper cadmium alloy workers studied in this cohort had excess risks of non-malignant diseases of the respiratory system rather than excess risks of lung cancer. Findings in relation to estimated cumulative exposures to cadmium were consistent with the hypothesis that exposure to cadmium oxide fume increases risks of mortality for chronic non-malignant diseases of the respiratory system.

We are grateful to Mr David O'Malley, former occupational hygienist for the factories under study, for information on how study materials were collected and historical process changes. We materials were collected and historical process changes. We thank the Office of Population Censuses and Surveys for tracing the study population and facilitating the double checking of the study files. We thank Professor Anthony Newman Taylor, Dr Malcolm Scott, and Dr David Gompertz for permission to access the in vivo data. We thank Margaret Williams 
for word processing, and Ivy Peck and Suvineetha Wanasundara for consolidation of data files. This update would not have been possible without a research award from the International Lead Zinc Research Organisation (ILZRO). TS receives generous financial support from the Colt Foundation. We thank the company management for access to company records. We acknowledge the importance of the work carried out by the late Dr Harry Holden.

1 Bonnell JA. Emphysema and proteinuria in men casting copper-cadmium alloys. Br f Ind Med 1955;12:181-95.

2 Bonnell JA, Kazantzis G, King E. A follow-up study of men exposed to cadmium oxide fume. Br f Ind Med 1959; exposed to

3 Holden H. A mortality study of workers exposed to cadmium fume. In: Cadmium 79, Edited Proceedings of the Second International Cadmium Conference, Cannes. London: Cadmium Association, 1980:211-5.

4 Holden H. Further mortality studies on workers exposed to cadmium fume. In: Occupational exposure to cadmium. London: Cadmium Association, 1980:23-4.

5 International Agency for Research on Cancer IARC Monographs on the evaluation of the carcinogenic risk of chemicals to humans. Vol 58. Beryllium, cadmium, mercury, and exposures in the glass manufacturing industry. Lyon: and exposures

6 Thun MJ, Schnorr TM, Smith AB, Halperin WE, Lemen RA. Mortality among a cohort of US cadmium production workers - an update. $\mathcal{F}$ Natl Cancer Inst 1985;74: 325-33

7 Stayner L, Smith R, Thun M, Schnorr T, Lemen R. A dose-response analysis and quantitative assessment of lung cancer risk and occupational cadmium exposure. Ann Epidemiol 1992;2:177-94.

8 Sorahan T, Lancashire R. Lung cancer findings from the NIOSH study of United States cadmium recovery workers: a cautionary note. Occup Environ Med 1994;51: 139-40.

9 Davison AG, Fayers PM, Newman Taylor AJ, Venables KM, Darbyshire J, Pickering CAC, et al. Cadmium fume inhalation and emphysema. Lancet 1988;i:663-7.

10 King E. An environmental study of casting coppercadmium alloys. Br $\mathcal{F}$ Ind Med 1955;12:198-205.

11 Coleman M, Douglas A, Hermon C, Peto J. Cohort study analysis with a Fortran computer program. Int $\mathcal{f}$ Epidemiol 1986:15:134-7.

12 Sorahan T, Cooke MA. Cancer mortality in a cohort of United Kingdom steel foundry workers: 1946-85. Br $\mathcal{F}$ Ind Med 1989;46:74-81.

13 Epicure. Seattle, USA: Hirosoft International Corporation, 1988.

14 Breslow NE, Day NE. Statistical methods in cancer research. Vol II. The design and analysis of cohort studies. Lyon: International Agency for Research on Cancer, 1987. (IARC Sci Publ No 82.)

15 Roels HA, Lauwerys RR, Buchet J, Bernard A, Chettle DR, Harvey TC. In vivo measurements of liver and kidney cadmium in workers exposed to this metal. Its significadmium in workers exposed to this metal. Its signifi-
cance with respect to cadmium in blood and urine. cance with respect to cadmiun
Environ Res 1981;26:217-40.

16 International Agency for Research on Cancer. IARC Monographs on the evaluation of the carcinogenic risk of chemicals to humans. Vol 23. Some metals and metallic compounds. Lyon: IARC, 1993.

\section{Instructions to authors}

Three copies of all submissions should be sent to: The Editor, Occupational and Environmental Medicine, BMJ Publishing Group, BMA House, Tavistock Square, London WC1H 9JR, UK. All authors should sign the covering letter as evidence of consent to publication. Papers reporting results of studies on human subjects must be accompanied by a statement that the subjects gave written, informed consent and by evidence of approval from the appropriate ethics committee. These papers should conform to the principles outlined in the Declaration of Helsinki (BMF 1964; ii:177).
If requested, authors shall produce the data on which the manuscript is based, for examination by the Editor.

Authors are asked to submit with their manuscript the names and addresses of three people who they consider would be suitable independent reviewers. They will not necessarily be approached to review the paper.

Papers should include a structured abstract of not more than 300 words, under headings of Objectives, Methods, Results, and Conclusions. Please include up to three keywords or key terms to assist with indexing. 